\title{
Foreword and acknowledgments
}

At a time when - in singular coincidence with the 50th anniversary of the Treaty of Rome - the future of the European construction is the subject of frequent discussions where further 'supranational' developments often meet resistance, this book wishes to be academically provocative: it formulates a legal case for supranational developments as the only solution that under certain conditions, in the current historical phase, would deserve being regarded as a way forward in two 'sensitive' areas of EC law such as EC company tax law and EC corporate law, and ultimately suggests that this would also be in all Member States' interests.

Given the dynamic areas of EC law at issue, the construction of this case required a critical review of the relevant EC legislation and case law, in order to demonstrate that a clear pattern could be identified and would require the proposed way forward, as well as to draw the arguments, and a considerable period of time. This started with my $\mathrm{PhD}$ thesis, prepared at the University of Essex and submitted in 2004, and finished in late October 2006 at the University of Leeds, when it was realized that few further developments taking place after the start of the production process on the main text, which had been presented at the end of May 2006, made it appropriate to add a short updating that the reader will find in Appendix VI. During such a considerable period of time, several people gave their contribution to the finalization of this book, and I would like to express sincere thanks to all of them.

This work was developed with my PhD thesis as a starting point and with considerable revisions and updating that were made necessary by ongoing developments in EC corporate law and EC company tax law and by the need to address the comments that I was aware that work could attract. Therefore, I'm extremely grateful, first, to Prof. Janet Dine, who, at the University of Essex Law Department, supervised both my LLM dissertation in 1996 and my $\mathrm{PhD}$ thesis during a period - from 2001 to 2004 - when I was carrying out my doctoral research on a part-time basis while working abroad. She had great patience in re-reading the changes that new pieces of EC legislation and new ECJ case law made necessary from time to time to parts that had already been written and, after her transfer to the Centre for Commercial Law Studies at the Queen Mary College, University of London, in 2005 felt that the work would deserve inclusion in the 'Corporations, Globalisation and the Law' series. My 
gratitude to Prof. Dine is equally due for her encouragement, before and after the publication in the Journal of Business Law in 1999 of a part of my LLM dissertation, to pursue the doctoral research itself, and for her reading of the last version of this work in June 2006. I also would like to thank, for their appreciating the $\mathrm{PhD}$ thesis and for the useful comments, the two examiners, Prof. Steve Peers (University of Essex) and Prof. Charlotte Villiers (University of Bristol), and I'm also obliged to the anonymous academic referee for Edward Elgar, whose comments were useful to me in the latest refinement phase.

As regards the technical phase of finalization of the book, I'm also very grateful to Elisabetta Valdani, at Essex University, who in 2005 helped me to understand the difficulties that would have arisen had an alternative procedure for the technical preparation of the manuscript been followed and who therefore allowed me to save enough time that I could devote to the updatings and revisions, and to the entire Edward Elgar team for their advice and patience before and after I submitted the manuscript. In particular, I wish to thank Luke Adams and Nep Elverd for their flexibility in extending the deadline initially agreed for submission and their patience with my numerous queries relating to technical house style criteria, and I'm also particularly grateful to Kate Emmins, who, during the later phase of the production process, allowed me to add the short updating appendix (October 2006) and was willing to discuss by phone, point by point, a series of questions concerning the way of expressing the arguments put forward, which issue, due to my not being a native English language speaker, was also important in my final check of corrections made in the previous copyediting phase.

As for some of the material used, I'm obliged to the International Bureau of Fiscal Documentation (IBFD) in Amsterdam, for authorizing me to use, in Chapter 4 paragraph 2 of this work, part of the material concerning the compatibility of tax competition with EC law, which was published in my previous article: L. Cerioni, 'Harmful tax competition revisited: Why not a Purely Legal Perspective under EC law?' European Taxation, the IBFD - edited and published journal in EC, comparative and international taxation, Vol. 45, No. 7, July 2005. I'm also grateful to Prof. Adriano Di Pietro and his collaborators at the University of Bologna, Faculty of Law, for providing me, shortly after the start of my work on the $\mathrm{PhD}$ thesis, with comparative material, drawn from international Congresses held there, concerning the implementation of the first two EC tax directives in several EC Member States. Last but not least, I'm also very grateful to my family of origin for allowing me, in 1995-1996, to attend the LLM in European Community Law at Essex University, which was the preliminary step for the research that led to the $\mathrm{PhD}$ thesis and 
eventually, through the work I carried out over the last two years, to this book.

Luca Cerioni

School of Law

University of Leeds

30 October 2006 
Luca Cerioni - 9781847205308

Downloaded from PubFactory at 04/26/2023 10:25:55AM 